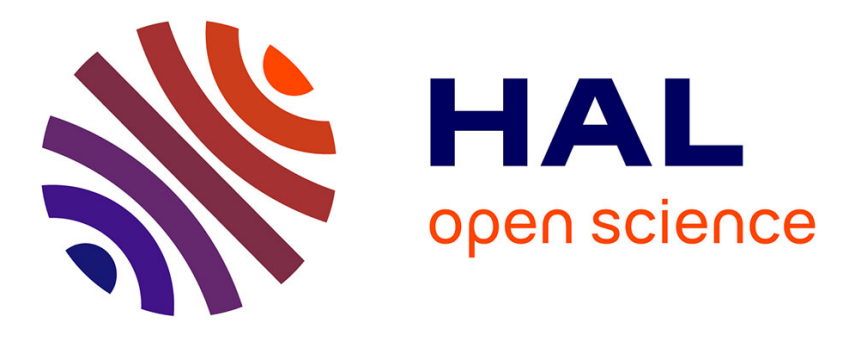

\title{
Separation of silicone oil droplets dispersed in activated sludge
}

\author{
Emanuel Granero-Fernandez, Eric Dumont, Charlotte Picard, Maxime \\ Guillerm, Emanuel Granero Fernandez, Christophe Stavrakakis, Edith \\ Norrant, Catherine Juery, Nicolas Lesage, Franck Rouxel, et al.
}

\section{To cite this version:}

Emanuel Granero-Fernandez, Eric Dumont, Charlotte Picard, Maxime Guillerm, Emanuel Granero Fernandez, et al.. Separation of silicone oil droplets dispersed in activated sludge. Separation Science and Technology, 2020, 55 (13), pp.2369-2380. 10.1080/01496395.2020.1758942 . hal-02886551v2

\section{HAL Id: hal-02886551 \\ https://hal.science/hal-02886551v2}

Submitted on 2 Mar 2021

HAL is a multi-disciplinary open access archive for the deposit and dissemination of scientific research documents, whether they are published or not. The documents may come from teaching and research institutions in France or abroad, or from public or private research centers.
L'archive ouverte pluridisciplinaire HAL, est destinée au dépôt et à la diffusion de documents scientifiques de niveau recherche, publiés ou non, émanant des établissements d'enseignement et de recherche français ou étrangers, des laboratoires publics ou privés. 


\section{Separation of silicone oil droplets dispersed in activated sludge}

Eric Dumont ${ }^{1}$, Charlotte Picard ${ }^{2}$, Maxime Guillerm ${ }^{2}$, Emanuel Granero Fernandez ${ }^{2}$, Christophe Stavrakakis $^{3}$, Edith Norrant ${ }^{4}$, Catherine Juery ${ }^{5}$, Nicolas Lesage ${ }^{6}$, Franck Rouxel ${ }^{7}$, Beatrice Balannec $^{2}$, Abdeltif Amrane ${ }^{2 *}$, Annabelle Couvert ${ }^{2}$

${ }^{1}$ UMR CNRS 6144 GEPEA, École des Mines de Nantes, La Chantrerie, 4 rue Alfred Kastler, B.P. 20722, 44307 Nantes Cedex 3, France

${ }^{2}$ Univ Rennes, Ecole Nationale Supérieure de Chimie de Rennes, CNRS, ISCR-UMR 6226, F35000 Rennes, France

${ }^{3}$ ADEME, 20 avenue du Grésillé, 49000 Angers

${ }^{4}$ UCB BioPharma sprl, Avenue de l'Industrie B 1420 Braine l'Alleud, Belgium

${ }^{5}$ TOTAL RC, CRES, chemin du canal BP22, 69360 Solaize, France

${ }^{6}$ Total S.A., CSTJF, Avenue Larribau, CA 374, 64018 Pau Cedex, France

${ }^{7}$ TC'Plastic, ZI de l'Abbaye, 44160 Pontchâteau, France

Short title: Separation of oil droplets from activated sludge.

Corresponding author: Phone: +33 2232381 55; Fax: +332232380 99;

Email: abdeltif.amrane@univ-rennes1.fr 


\begin{abstract}
A process in three steps involving a gas-liquid contactor with an organic phase, a TPPB and a liquid/liquid separator to recover the organic phase for its recycling was proposed to treat hydrophobic Volatile Organic Compounds. Among the processes tested for liquid/liquid separation (settling, hydrocyclone and centrifugation), the latter appeared to be the most efficient. The centrifugal acceleration needed for the separation of oil and water was found to be dependent on the viscosity of the oil used and the presence of microorganisms. The force required for phases' separation was found to be reduced in the presence of selected commercial demulsifiers.
\end{abstract}

Keywords: Activated sludge; Emulsion; Liquid/liquid Separation; Silicone oil; Toluene.

\title{
1 Introduction
}

Atmospheric pollution is one of the major issues in terms of environment. Several conferences (New York, 1997; Rio 1992; Paris Climate Conference 2015) highlighted the importance of reducing the emission of Volatile Organic Compounds (VOCs). It is possible to classify the processes of purification of gas loaded with VOCs in three groups: thermal treatment (incineration and condensation), mass transfer processes with or without chemical reactions (adsorption, absorption, membranes) and finally biological systems (biofilters, biotrickling filters and bioscrubbers) [1]. Biological treatments are interesting to eliminate non recoverable compounds at low cost, but they are not applicable for all VOCs. These latter have to be available in the aqueous phase, biodegradable and not toxic towards biomass. Then, the performances of conventional bioprocesses are restricted to some families of compounds, and do not match with hydrophobic VOCs. 
Then, the addition of an organic phase, immiscible with the aqueous phase, should allow the absorption of high amounts of VOCs [2]. VOCs dissolved in the organic phase are in equilibrium with the aqueous phase owing to mass transfer from the organic to the aqueous phase. The concentration of VOCs remains low owing to their hydrophobicity, and hence non toxic for biomass. The organic phase acts therefore as a reservoir of pollutants [3-5]. Such multiphase reactor is named Two Phase Partitioning Bioreactor (TPPB) [6]. To date, silicone oils have been identified as the best organic solvents for the biological treatment of hydrophobic VOC [7]. To treat such compounds, a process in three steps is proposed (Figure 1): the first one is a gas / liquid contactor dedicated to the transfer of the VOC from the gaseous phase to the organic phase; the second step is a TPPB dedicated to the degradation of the VOC contained in the organic phase (either transferred in the aqueous phase, or at the liquid / liquid interface); and the last step is a liquid / liquid separator aiming at recovering the organic phase and reusing it at the inlet of the whole process [7,8]. Taken into account the cost of the silicone oil [9], the separation step between oil and water is of main importance for the viability of the process at industrial scale. The aqueous phase containing the biomass is partially recycled in the TPPB. In the TPPB, the organic phase is dispersed in the aqueous phase into droplets which are stabilized by the biomass itself or by surfactants produced by the biomass. Indeed, biomass is able to produce high and low molecular mass surfactants which can be peptides, saccharides or lipids or their combination. Biosurfactants can be divided into low molecular mass molecules, which efficiently decrease surface and interfacial tensions, and high molecular mass polymers, which tightly bind surfaces. They are produced by a wide variety of diverse microorganis ms [10]. Moreover, the amount and the type of biosurfactants produced depend on the carbon and the nitrogen sources used by the biomass (i.e. the $\mathrm{C} / \mathrm{N}$ ratio), the temperature, the aeration and the $\mathrm{pH}$ [11-13]. Some bacterial cells are able to stabilize oil-in-water emulsions themselves and therefore behave as fine solid particles at the interface [5,14]. Moreover, Marin et al. [15] 
observed bacteria clustering around oil droplets and eventually embedded in a polymer sheet forming then a complex network.

According to the process presented in Figure 1, the oil is recycled. Then, a coalescence of the oil droplets after the TPPB is necessary in order to separate the oil phase from the aqueous phase. This liquid / liquid separation can be performed according to various processes. Evaporation (or vacuum evaporation) consists in an increase of the temperature of the emulsion leading to the break of the emulsion, and then water vaporization. This process allows producing an aqueous effluent of excellent quality, leaving low water content in the final oily phase $[16,17]$. However, in the present case, the biomass present in the aqueous phase most likely stays in the organic phase (at the interface), disturbing the recirculation of the phases by fouling the gas/liquid contactor. Moreover, this process presents a high energy consumption compare to other techniques. Membrane technology can be a cheaper alternative method for separating emulsions. Examples of separation have been reported in the literature: pervaporation, reverse osmosis, ultrafiltration and microfiltration [18-21]. The continuous phase is driven through the membrane by the application of a transmembrane pressure and the dispersed phase is retained at the surface of the membrane. But the quality of the flux declines with time, which could be attributed to (i) surfactant adsorption on the pore walls; (ii) the presence of a polarized layer of concentrated emulsion at the membrane surface and (iii) pore plugging by oil droplets $[22,23]$. The separation of oil in water emulsion would involve the utilization of a hydrophilic membrane. However, as the biomass produces surfactants and bacteria are amphiphilic, a decrease of the hydrophobicity of the membrane by adsorption might be achieved. Moreover, the main drawback of this technology is that the membrane may retain the oil and the biomass [24], while the objective is that the biomass cross the membrane with the aqueous phase. 
In the frequent case where the two phases present a difference of electrical conductivity, it is possible to separate them by application of an electric field. This electrochemical destabilization (electrocoagulation) does not need any chemical additive. When direct current is applied to water through a pair of metallic electrodes, the anode is dissolved to produce metal ions. Then, the electro-generated cations neutralize the surface charge on the surfactant molecules around the oil droplets, and as a result, the emulsion is destabilized and the colloidal oil particles begin to coalesce [25-27]. However, this process consumes lots of energy and is not well adapted to high volume.

Otherwise, liquid separation can be based on the difference of densities between phases using gravitational acceleration (decantation) or centrifugal acceleration. Settlers are known for their relative ease of design and versatility, but they require a large floor-space and often decantation is a long process. Usually, the demulsification time of surfactant-stabilized emulsions by decantation may be of order of magnitude larger than their residence time in the separator. There is therefore a high interest in increasing the gravitational force by centrifugation. Centrifugation is a compact process requiring lower time of operation compared to settling. The tangential force acting on the droplets can be hundreds of times higher than the normal gravitational acceleration of decantation. The collisions between the droplets are expected to be more efficient and to cause an increase of coalescence [28,29]. Although centrifugation technology is an attractive method, it requires nonetheless high energy levels.

Liquid separation can also be performed using hydrocyclones. This technology is based on the energy of the fluid in order to generate a vortex effect. The oil droplets move toward the wall or the center of the vortex depending on their density, and they undergo a centrifugal acceleration increasing coalescence [30].

Finally, it is possible to separate the phases using chemical agents (salts and polymers) called demulsifiers. The efficiency of the salts is linked to the valence of its cation [27]. Moreover, 
their presence influences the zeta potential of the droplets and the breakup of the emulsion is due to the reduction of the surface charge of the droplets. Polymer demulsifiers can be cationic, ionic or nonionic. These molecules are able to modify the characteristics of the oil-water interface film (the interfacial rheology and the dynamic interfacial tension), allowing the coalescence of the droplets [31-33]. Besides, the demulsifier concentration influences the separation efficiency. Pincus et al. [34] suggested that increasing the concentration improves the emulsion separation and Wang et al. [35] showed the existence of an optimum value which is specific of each solution of droplets and polymers. Furthermore, Krawczyk et al. [36] showed that the partitioning of the demulsifier between the oil phase and the aqueous phase influence the efficiency of the separation. An equal partition of the demulsifier between phases seems to improve the efficiency. Moreover, the molecular size of demulsifiers is a factor influencing their efficiency [32]. This is why, usually, commercial demulsifiers are blended mixtures of several components with various chemical structures, polymeric materials and weight distribution. As a result, their efficiency can only be measured carrying out experiments on a given emulsion.

The goal of this work was to determine the most appropriate liquid / liquid separator after stabilization of the oil droplets in the ТРPВ. As the most appropriate process to separate the phase uses gravity or an increase of the gravitational force, 3 technologies were tested for separation, i.e. settling, centrifugation and hydrocyclone. Addition of chemical demulsifiers was also tested in order to determine their influence on the droplet coalescence. For each experiment, the oil in water dispersion was characterized in order to evaluate the impact of physico-chemical modifications of the dispersion. 


\section{Experimental}

\subsection{Dispersion formation}

The dispersion of oil in water was performed in Erlenmeyers. Silicone oils (Rhodorsil oils from Bluestar Silicones Company), whose characteristics are presented in Table 1, have been used. $100 \mathrm{~mL}$ of oil was introduced in a $1 \mathrm{~L}$ Erlenmeyer. Then, $300 \mathrm{~mL}$ of water containing $0.5 \mathrm{~g} \mathrm{~L}^{-}$ ${ }^{1}$ of activated sludge from the wastewater treatment plant of Rennes (France) and minerals (Tables 2 and 3) was added. The Erlenmeyers were closed with a rubber top or a cellulosic top before introducing toluene through a derivation. Erlenmeyers were then incubated at $25^{\circ} \mathrm{C}$ under agitation (300 rpm) for 8 days. Toluene $\left(\mathrm{C}_{7} \mathrm{H}_{8}\right.$, Fisher Chemicals, 99\%) was chosen as carbon source for biomass development because it is a highly hydrophobic and commonly used in TPPB studies as target VOC. The biomass activity was then quantified by the change in the toluene concentration in the gas phase. Toluene concentration was measured using a gas chromatography (Thermo Scientific, Focus GC, FID detector) by daily sampling of the gas phase in the Erlenmeyers. Figure 2 shows the toluene consumption by activated sludge. Based on the control, losses of about $20 \%$ could be highlighted. On day $3,500 \mu \mathrm{L}$ of toluene were added in order to feed the biomass with carbon and so to let time to dispersion formation. According to Figure 2, the blank solution shows that the leaks of toluene are clearly smaller than its consumption confirming the use of toluene as a carbon source.

\subsection{Assessment of the separation quality}

As the aim of this work was to determine the most appropriate liquid / liquid separator of the emulsion, a homemade method to assess the efficiency of the separation was developed. The separation quality was evaluated using a scale developed as described in Table 4. This scale allowed to rate each parameter characterizing the separation efficiency by attributing a note from 1 to 5 . The score of each parameter was weighted to give an average score and quantify 
the separation efficiency (Table 4). The higher the score was, better was the efficiency. The accuracy of the method was evaluated to be equal to $\pm 5 \%$.

\subsection{Determination of the oil properties}

The viscosity was measured using a viscometer (Brookfield, CV-II+, viscometer-Labomat) and the density was quantified using a pycnometer (Brand) and a precision balance $\left(10^{-4} \mathrm{~g}\right)$. The interfacial tension existing between oil and water was measured using a force tensiometer (Kruss K100SF). Two kinds of oils were considered, new oil and used oil, namely oil which has been in contact with biomass several times (at least one time).

\subsection{Demulsifier addition and assessment}

Thirteen commercial demulsifier solutions were tested in order to perform the separation of the emulsions generated in the Erlenmeyers. For confidential reasons, the names of these products are not given, and have been replaced by letters. Each demulsifier was added to the solutions (from 0 to $200 \mathrm{mg} \mathrm{L}^{-1}$ ), which were then agitated during 30 minutes. In order to quantify the role of demulsifiers using the method presented earlier, the dispersions formed in the Erlenmeyers were carefully and faithfully split in tubes of $50 \mathrm{~mL}$. Then, the oil and aqueous phases were separated using a centrifuge during $10 \mathrm{~min}$ (Sigma Laboratory, 6K15, centrifugal acceleration from $500 \mathrm{~g}$ to $5000 \mathrm{~g}$ ).

The demulsifier partitioning between oil and water was also evaluated. For this purpose, the dispersion of oil in water was prepared with $25 \%$ of oil and $75 \%$ of ultra-pure water. Due to the method used for partitioning assessment, experimentations were carried out without biomass in order to avoid bias in measurement. On a first approach, it was assumed that the presence of biomass has no influence in partitioning value. A known amount of demulsifier, corresponding 
to a given amount of Chemical Oxygen Demand (COD), was added to the dispersions and a dispersion without demulsifier addition was used as a control. The solutions were agitated during one day. Then, the COD was spectrophotometrically measured in the aqueous solution using kits (Nanocolor 500D, Marchery Nagel), and the distribution of the demulsifier in each phase was evaluated from the following equations:

$$
\begin{aligned}
& C O D_{D W}=\frac{C O D_{W} V_{W}-C O D_{O W} V_{O}}{V_{W}} \\
& C O D_{D O}=\frac{C O D_{D} V_{W}-\operatorname{COD}_{D W} V_{W}}{V_{O}}
\end{aligned}
$$

where:

CODDw and CODDo are the chemical oxygen demands of the demulsifier dissolved in the water phase and in the oil phase respectively $\left(\mathrm{mg} \mathrm{L}^{-1}\right)$.

$\mathrm{COD}$ is the chemical oxygen demand measured in the aqueous phase corresponding to the carbon due to the demulsifier $\left(\mathrm{mg} \mathrm{L}^{-1}\right)$.

CODow is the chemical oxygen demand of the oil dissolved in water $\left(\mathrm{mg} \mathrm{L}^{-1}\right)$.

$\mathrm{COD}_{\mathrm{D}}$ is the total chemical oxygen demand of the demulsifier of the aqueous phase before its contact with the oil $\left(\mathrm{mg} \mathrm{L}^{-1}\right)$.

$\mathrm{V}_{\mathrm{W}}$ and $\mathrm{V}_{\mathrm{O}}$ are the volumes of the aqueous and oil phases, respectively (L).

The demulsifier biodegradability was evaluated from measurements of the Biological Oxygen Demand after 5 days (BOD5) carried out with Oxitop IS6 (WTW, Alès, France). Each flask used $(164 \mathrm{~mL})$ contained $0.034 \mathrm{~g} \mathrm{~L}^{-1}$ of $\mathrm{MgSO}_{4}, 7 \mathrm{H}_{2} \mathrm{O} ; 0.042 \mathrm{~g} \mathrm{~L}^{-1} \mathrm{CaCl}_{2} ; 2.3 \times 10^{-3} \mathrm{~g} \mathrm{~L}^{-1}$ of $\mathrm{FeCl}_{3} ; 3 \times 10^{-3} \mathrm{~g} \mathrm{~L}^{-1}$ of $\mathrm{NH}_{4} \mathrm{Cl} ; 0.05 \mathrm{~g} \mathrm{~L}^{-1}$ of $\mathrm{Na}_{2} \mathrm{HPO}_{4} ; 0.02 \mathrm{~g} \mathrm{~L}^{-1}$ of $\mathrm{KH}_{2} \mathrm{PO}_{4}$ and $0.006 \mathrm{~g} \mathrm{~L}^{-1}$ of dry matter of activated sludge. The sampling volume of the solution introduced in the flask was deduced from the measurement of the COD of the solution. A solution of $\mathrm{N}$-allylthio urea was added as nitrification inhibitor $\left(10 \mathrm{mg} \mathrm{L}^{-1}\right)$. Then, the demulsifier was added. Two flasks were used for each demulsifier solution. 
A similar protocol was used for two control flasks containing easily biodegradable compounds (glutamic acid and glucose at $130 \mathrm{mg} \mathrm{L}^{-1}$ each) instead of demulsifiers. A blank test was also performed without the addition of carbon in a volume of $432 \mathrm{~mL}$ of saline solution in order to evaluate the endogenous respiration $\left(\mathrm{DBO}_{5}{ }^{\mathrm{END}} ; \mathrm{mg} \mathrm{L}^{-1}\right)$. The $\mathrm{pH}$ was initially adjusted to 7 for each flask. Biodegradability was evaluated by means of the following equation 3:

Biodegradability $=\frac{B O D_{5}-B O D_{5}^{E N D}}{C O D}$

Two sets of experiments were performed in order to evaluate the demulsifier toxicity. Glass bottles of $22 \mathrm{~mL}$ were filled with $5 \mathrm{~mL}$ of aqueous solution (Table 2), $0.5 \mathrm{~g} \mathrm{~L}^{-1}$ of dry suspended matter and $1.7 \mathrm{~mL}$ of oil. Each demulsifier was added at a concentration of $1000 \mathrm{mg} \mathrm{L}^{-1}$. One bottle was used free from demulsifier and one bottle free from both demulsifier and biomass. The bottles were closed with PTFE-coated silicone rubber septa (Perkin, Elmer, France) and sealed with aluminum caps. Then $1 \mu \mathrm{L}$ of liquid toluene was injected into each bottle. The bottles were incubated at $25^{\circ} \mathrm{C}$ under agitation (300 rpm) and the toluene concentration in the headspace was periodically analyzed by gas chromatography.

The activated sludge distribution between the aqueous and oil phases was also quantified. Dispersions of oil in water in the presence of the biomass formed according to the protocol described in section 2.1 were used. Demulsifiers were added, and the dispersion was agitated for 1 hour at $300 \mathrm{rpm}$. Then, the oil and aqueous phases were separated by centrifugation (20000 g, $20 \mathrm{~min}$ ). The centrifugate of the aqueous phase was at the bottom of the bottle. Some sludge stayed at the oil and water interface were considered to be part of the organic phase. The centrifugate of each phase was rinsed with ultra pure water and centrifuged again. The centrifugate was then dried at $105^{\circ} \mathrm{C}$ for 10 hours and weighed to obtain the amount of suspended solids. 


\section{Results and discussion}

\subsection{Characterization of the oil in water dispersion}

The characterization was carried out using the Rhodorsil oil 47v5. The interfacial tension between oil (new and used oil) versus water containing salts was lower than that versus ultrapure water (Figure 3). Indeed, the presence of salts in water is likely to modify the surface and interfacial tension [38]. The interfacial tension between new oil and water containing biomass was also lower than that observed in the presence of salts (the interfacial tension between used oil and water containing biomass was not measured). It could be due either to the biomass itself which is able to cling to the interface [15] or to biosurfactants produced by the biomass $[10,13]$. Figure 3 also put in evidence that the use of used oil decreased the interfacial tension between oil and water. Even if the interfacial tension between used oil and water containing biomass was not measured, it could be argued that the value should be slightly lower than the value obtained for new oil. This could be due to oil-soluble molecules produced by biomass. For this reason, the oil density and viscosity were measured before and after contact with the biomass. After contact with the biomass, the dynamic viscosity of oil increased from 5 to $6 \mathrm{mPa} . \mathrm{s}(+20 \%)$, showing an apparent effect of the biomass. Conversely, after contact with biomass, the density of used oil appeared not significantly different to that of new oil $\left(910 \mathrm{~kg} \cdot \mathrm{m}^{-}\right.$

3; Table 1). These results show that the biomass can impact the properties of the oil and increase the stability of the emulsion, but without influencing significantly the industrial cost (due for instance to pumping). An analytical analysis would be interesting to identify the molecules responsible of the increase of the oil viscosity; however such study appears out of the scope of the present study. The effect of the presence of salts and biomass in the aqueous media on the separation by settling and centrifugation was evaluated using the scale evaluation reported in Table 4. 


\subsection{Separation by settling}

In order to test the separation by settling, the dispersion formed was versed in a separator funnel and the settling was operated for ten days. When oil and ultra-pure water are mixed, their separation can easily be performed by settling. However, the presence of salts in water stabilizes the emulsion making the separation difficult [38]. An illustration of such separation is given by the picture displayed in Figure 4. A thin (micrometer size) film of oil on the top can be observed, as well as a layer of oil in the water dispersion. After ten days, no more change in the dispersion could be noticed showing the lack of efficiency of settling in our time scale process. Settling was therefore discarded as a possible separation system. As a result, the separation has to be done through physical or chemical process.

\subsection{Separation by centrifugation}

\subsubsection{Centrifugation without demulsifier}

The effect of the presence of salts in the aqueous media on the separation by centrifugation was evaluated for different acceleration rates (Figure 5). This figure shows that the components of the emulsion can be efficiently separated by centrifugation. However, the presence of microorganisms in the salt solution (after 8 days of agitation) increased the stability of the dispersion and hence decreased the efficiency of the separation. This could be due to the microorganisms themselves or bio-surfactants produced by these latter [39-41].

The literature reports that the diameter of the oil droplets generated during emulsion agitation decreased when the agitation speed increased $[42,43]$. In order to test the centrifugation efficiency, oil in water dispersions (Rhodorsil oil 47v5) were prepared at three agitation speeds before separation (i.e. 200, 300 and $550 \mathrm{rpm}$ ). The centrifugal acceleration necessary to separate the phases are given in Table 5. Below the given range of values, the phases are not separated, while over the higher value a clear separation between both phases can be observed. In 
agreement with the literature data, the value of the centrifugal acceleration necessary for the separation of phases increased with the agitation speed used for dispersion generation.

The effect of oil viscosity on the separation efficiency was investigated for the oil in water dispersions formed at $300 \mathrm{rpm}$ using the three silicone oils presented in the Table 1 . Table 6 shows that an increase of the viscosity from 5 to $50 \mathrm{mPa} \mathrm{s}$ implied an increase of the centrifugation rate needed for an efficient separation. For viscosity higher than $50 \mathrm{mPa} \mathrm{s}$, centrifugation rate has not to be increased.

\subsubsection{Centrifugation with demulsifier}

The separation efficiency of centrifugation in the presence of a chemical demulsifier in the emulsion has been measured for 13 different demulsifiers. Figure 6 presents an example of the qualitative note of the separation for different concentrations of the demulsifier and for 3 centrifugation rates. According to this figure, the best separation was reached for a demulsifier concentration of $15 \mathrm{mg} \mathrm{L}^{-1}$. Moreover, from $500 \mathrm{~g}$ to $750 \mathrm{~g}$, the separation efficiency increased with the centrifugation rate, but there is no significant difference between $750 \mathrm{~g}$ and $1000 \mathrm{~g}$. As a result, and in comparison with the results obtained without demulsifier (Figure 5), it can be concluded that demulsifier addition allows to significantly reduce the centrifugation rate needed for separation. Among the 13 commercial demulsifiers tested, 3 were retained for their efficiency to achieve separation. In order to be used at industrial scale in the presence of microorganisms, the biodegradability, the toxicity and the distribution of these 3 demulsifiers (symbolized by letters A to $\mathrm{C}$ hereinafter) between oil and water phases were tested.

\subsubsection{Biodegradability, toxicity and demulsifier distribution}

For the three products $\mathrm{A}, \mathrm{B}$ and $\mathrm{C}$, the demulsifier distribution between the oil and water phases was determined according to the procedure described in the part 2.4. Experimental results show 
that the 3 selected demulsifiers were mainly found in the aqueous phase, for more than $90 \%$ (Figure 7). Although the names of the demulsifiers cannot be given for confidential reasons, this finding was expected because these products are cationic polymers soluble in water.

The biodegradability of the three demulsifiers was evaluated based on the ratio $\mathrm{COD} / \mathrm{BOD}_{5}$. A high ratio is desired, on the one hand, in order to avoid a possible consumption of the demulsifier as carbon source in competition with the VOC, and on the other hand, for economic considerations in view of their recycling into the aqueous phase in the TPPB. The calculated values of the ratio $\mathrm{COD} / \mathrm{BOD}_{5}$ were 19, 104 and 2003 for demulsifiers $\mathrm{A}, \mathrm{B}$ and $\mathrm{C}$ respectively. As ratios are superior to 3 , the non-biodegradability of the 3 demulsifiers is proven [44]. In order to assess the toxicity of the three demulsifiers towards microorganisms, the consumption of the toluene by the biomass was evaluated for 2 days. Figure 8 shows the evolution of the toluene concentration in the gas phase in the presence and the absence of demulsifier. A blank (nor microorganisms neither demulsifier) was used to evaluate toluene leaks. For each case studied, duplicate experiments were performed. In the absence of demulsifier and biomass, the toluene concentration decreased from $30 \mathrm{~h}$ of culture until reaching $60 \%$ of the initial concentration. In the presence of demulsifiers $\mathrm{A}$ and $\mathrm{B}$, about $20 \mathrm{~h}$ lag phase was observed and toluene was completely removed after $32 \mathrm{~h}$. The demulsifier $\mathrm{C}$ showed a different behavior since biodegradation started only after $50 \mathrm{~h}$, and removal yield were in the range 50 to $80 \%$ of the initial toluene amount. From this, a clear inhibitory effect was shown for this demulsifier, which is not acceptable for possible implementation in the considered process.

The activated sludge distribution between the aqueous and oil phases was also evaluated in the absence and the presence of the demulsifiers. The objective was to minimize the amount of biomass in the oil phase. The results obtained from duplicate experiments showed that with demulsifier B, the biomass settled more than with demulsifiers A and C. An additional 
experiment was carried out by adding ultrapure water to the oil phase after separation of the phases. The oil and the water were then shaken and the activated sludge in each phase was evaluated again. The results showed that $40 \%$ of the sludge present in the oil phase was transferred to the aqueous phase used for washing. This part of transferred sludge represented around $6 \%$ of the total sludge initially present in the dispersion. Consequently, and according to this result, at an industrial scale, the addition of a tank for agitation and decantation before the centrifugation would allow to significantly decrease the amount of activated sludge in the oil phase.

\subsection{Separation by hydrocyclone}

A modeling study has been done in order to evaluate the feasibility of using a hydrocyclone to separate the phases. This study is based on the model proposed by Amini et al. [45] involving the Comsol software. The model allows to determine the trajectory of the oil droplets inside the hydrocyclone and the acceleration they undergo. The dimensions of the hydrocylone used for the study (Figure 9) are given in the Table 7. The purpose of this modeling was to determine the acceleration underwent by the fluids inside the hydrocyclone (Figure 10). Nowadays, models are not able to predict the coalescence of oil droplet but can be helpful to determine the trajectories of the oil droplets as a function of their size. The model shows that the hydrocyclone cannot allow to achieve a separation between the oil and water phases for droplets with a diameter smaller than $10 \mu \mathrm{m}$, because some of them leave the hydrocyclone in the aqueous phase. Over $10 \mu \mathrm{m}$ diameter, all the oil droplets leave the hydrocyclone in the oil phase. However, with the increase of the oil droplet diameter, the oil leaves the system without undergoing high acceleration, and as a result, for droplets over $500 \mu \mathrm{m}$ of diameter, the hydraulic retention time inside the hydrocyclone was too low to achieve significant acceleration. From the emulsions performed according to the procedure described in the part 
2.1., the size of the oil droplets and the droplet size distribution were experimentally measured using a Mastersizer (Malvern Instruments 2000). Results are presented at the Figure 11. The average diameter of the oil droplets was found to be $310 \mu \mathrm{m}$, while the distribution was found to follow a Gaussian-type. According to the results of the model, it appears that most of the droplets should leave the hydrocyclone without achieving the acceleration needed for coalescence. As a result, hydrocyclone could not be used for the liquid / liquid separation at industrial scale.

\section{Conclusion}

In view of the use TPPB for the treatment of gas containing hydrophobic VOC, water and oil phases need to be separated with the aim of oil recycling. It was observed that the stability of the emulsion of oil droplets dispersed in the water phase was due to the presence of salts, as well as biomass, in water. Moreover, this stability increased with the stirring speed of the TPPB as well as with the viscosity of the oil phase. As a result, centrifugation appeared to be the most efficient separation process for the use of TPBB at industrial scale. The centrifugal acceleration needed for the separation of oil and water mixtures was found to be dependent on the viscosity of the oil used, as well as the presence of microorganisms which increased the stability of the emulsion. The addition of demulsifier has also to be considered in order to decrease the force required for the separation of phases. The distribution of the demulsifier between the oil and water phases, the toxicity of the demulsifiers toward biomass and the biodegradability of the demulsifiers allowed selecting 2 demulsifiers which could be subsequently tested at pilot scale for the separation of liquid phases.

\section{Acknowledgments}

The authors would like to thank the French agency for the Environment and the control of Energy (ADEME) for their financial support through a postdoctoral fellowship for C. Picard. 


\section{References}

[1] Le Cloirec, P. (1998) Les composés organiques volatils dans l'environnement. TEC\&DOC, London, Paris, New-York.

[2] Cesário, M.T.; Beeftink, H.H.; Tramper, J. (1995) Feasibility of using water-immiscible organic solvents in biological waste-gas treatment. Bioprocess Eng., 12: 55-63.

[3] Collins, L.D.; Daugulis, A.J. (1997) Biodegradation of phenol at high initial concentrations in two-phase partitioning batch and fed-batch bioreactors. Biotechnol. Bioeng., 55: 155-162.

[4] Collins, L.D.; Daugulis, A.J. (1999) Simultaneous biodegradation of benzene, toluene, and p-xylene in a two-phase partitioning bioreactor: concept demonstration and practical application. Biotechnol. Prog., 15: 74-80.

[5] Hori, K.; Hiramatsu, N.; Nannbu, M.; Kanie, K.; Okochi, M.; Honda, H.; Watanabe, H. (2009) Drastic change in cell surface hydrophobicity of a new bacterial strain, Pseudomonas sp. TIS1-127, induced by growth temperature and its effects on the tolueneconversion rate. J. Biosci. Bioeng., 107: 250-255.

[6] Daugulis, A.J. (2001) Two-phase partitioning bioreactors: a new technology platform for destroying xenobiotics. Trends Biotechnol., 19: 457-462.

[7] Darracq, G.; Couvert, A.; Couriol, C.; Amrane, A.; Thomas, D.; Dumont, E.; Andrès, Y.; Le Cloirec, P. (2010) Silicone oil: An effective absorbent for the removal of hydrophobic volatile organic compounds. J. Chem. Technol. Biotechnol., 85: 309-313.

[8] Arriaga, S.; Muñoz, R.; Hernández, S.; Guieysse, B.; Revah, S.; (2006) Gaseous hexane biodegradation by Fusarium solani in packed-bed and stirred tank bioreactors with two liquid phases. Environ. Sci. Technol., 40 (7): 2390-2395

[9] Dumont, E.; Darracq, G.; Couvert, A.; Couriol, C.;Amrane, A.; Thomas, D.; Andrès, Y.; Le Cloirec, P. (2011) VOC absorption in a countercurrent packed-bed column using 
water/silicone oil mixtures: Influence of silicone oil volume fraction. Chem. Eng. J., 241248

[10] Rosenberg, E.; Ron, E.Z. (1999) High- and low-molecular-mass microbial surfactants. Appl. Microbiol. Biotechnol., 52: 154-162.

[11] Desai, J.D.; Banat, I.M. (1997) Microbial production of surfactants and their commercial potential. Microbiol. Mol. Biol. Rev. MMBR., 61: 47-64.

[12] Martínez-Checa, F.; Toledo, F.L.; Vilchez, R.; Quesada, E.; Calvo, C. (2002) Yield production, chemical composition, and functional properties of emulsifier H28 synthesized by Halomonas eurihalina strain H-28 in media containing various hydrocarbons. Appl. Microbiol. Biotechnol., 58: 358-363.

[13] Toledo, F.L.; Gonzalez-Lopez, J.; Calvo, C. (2008) Production of bioemulsifier by Bacillus subtilis, Alcaligenes faecalis and Enterobacter species in liquid culture. Bioresour. Technol., 99: 8470-8475.

[14] Dorobantu, L.S.; Yeung, A.K.C.; Foght, J.M.; Gray, M.R. (2004) Stabilization of oil-water emulsions by hydrophobic bacteria. Appl. Environ. Microbiol., 70: 6333-6336.

[15] Marin, M.; Pedregosa, A.; Laborda, F. (1996) Emulsifier production and microscopical study of emulsions and biofilms formed by the hydrocarbon-utilizing bacteria Acinetobacter calcoaceticus MM5. Appl. Microbiol. Biotechnol., 44: 660-667.

[16] Gutiérrez, G.; Cambiella, Á.; Benito, J.M.; Pazos, C.; Coca, J. (2007) The effect of additives on the treatment of oil-in-water emulsions by vacuum evaporation. J. Hazard. Mater., 144: 649-654.

[17] Gutiérrez, G.; Lobo, A.; Benito, J.M.; Coca, J.; Pazos, C. (2011) Treatment of a waste oilin-water emulsion from a copper-rolling process by ultrafiltration and vacuum evaporation. J. Hazard. Mater., 185: 1569-1574. 
[18] Scott, K.; McConvey, I.F.; Adhamy, A. (1992) Application of crossflow microfiltration to emulsion separation in extraction processes. J. Membr. Sci., 72: 245-257.

[19] Koĺtuniewicz, A.B.; Field, R.W. (1996) Process factors during removal of oil-in-water emulsions with cross-flow microfiltration. Desalination, 105: 79-89.

[20] Tirmizi, N.P.; Raghuraman, B.; Wiencek, J. (1996) Demulsification of water/oil/solid emulsions by hollow-fiber membranes. AIChE J., 42: 1263-1276.

[21] Sirkar, K.K. (1997) Membrane Separation Technologies: Current Developments. Chem. Eng. Commun., 157: 145-184.

[22] Lee, S.; Aurelle, Y.; Roques, H. (1984) Concentration polarization, membrane fouling and cleaning in ultrafiltration of soluble oil. J. Membr. Sci., 19: 23-38.

[23] Lipp, P.; Lee, C.H.; Fane, A.G.; Fell, C.J.D. (1988) A fundamental study of the ultrafiltration of oil-water emulsions. J. Membr. Sci., 36: 161-177.

[24] Albasi, C.; Bessiere, Y.; Desclaux, S.; Remigy, J.C. (2002) Filtration of biological sludge by immersed hollow-fiber membranes: influence of initial permeability choice of operating conditions. Desalination, 146: 427-431.

[25] Yang, C.-L. (2007) Electrochemical coagulation for oily water demulsification. Sep. Purif. Technol., 54: 388-395.

[26] Tir, M.; Moulai-Mostefa, N. (2008) Optimization of oil removal from oily wastewater by electrocoagulation using response surface method. J. Hazard. Mater., 158: 107-115.

[27] Cañizares, P.; Martínez, F.; Jiménez, C.; Sáez, C.; Rodrigo, M.A. (2008) Coagulation and electrocoagulation of oil-in-water emulsions. J. Hazard. Mater., 151: 44-51.

[28] Cambiella, A.; Benito, J.M.; Pazos, C.; Coca, J. (2006) Centrifugal Separation Efficiency in the Treatment of Waste Emulsified Oils. Chem. Eng. Res. Des., 84: 69-76.

[29] Krebs, T.; Schroën, C.G.P.H.; Boom, R.M. (2012) Separation kinetics of an oil-in-water emulsion under enhanced gravity. Chem. Eng. Sci., 71: 118-125. 
[30] Wolbert, D.; Ma, B.-F.; Aurelle, Y.; Seureau, J. (1995) Efficiency estimation of liquidliquid Hydrocyclones using trajectory analysis. AIChE J., 41: 1395-1402.

[31] Kim, Y.H.; Wasan, D.T.; Breen, P.J. (1995) A study of dynamic interfacial mechanisms for demulsification of water-in-oil emulsions. Colloids Surf. Physicochem. Eng. Asp., 95: 235-247.

[32] Sun, T.; Zhang, L.; Wang, Y.; Zhao, S.; Peng, B.; Li, M.; Yu, J. (2002) Influence of demulsifiers of different structures on interfacial dilational properties of an oil-water interface containing surface-active fractions from crude oil. J. Colloid Interface Sci., 255: $241-247$.

[33] Kang, W.; Guo, L.; Fan, H.; Meng, L.; Li, Y. (2012) Flocculation, coalescence and migration of dispersed phase droplets and oil-water separation in heavy oil emulsion. $J$. Pet. Sci. Eng., 81: 177-181.

[34] Pincus, G.; Hechter, O.; Zaffaroni, A. (1951) Second Conference on Clinical ACTH. London.

[35] Wang, Y.; Zhang, L.; Sun, T.; Zhao, S.; Yu, J. (2004) A study of interfacial dilational properties of two different structure demulsifiers at oil-water interfaces. J. Colloid Interface Sci., 270: 163-170.

[36] Krawczyk, M.A.; Wasan, D.T.; Shetty, C. (1991) Chemical demulsification of petroleum emulsions using oil-soluble demulsifiers. Ind. Eng. Chem. Res., 30: 367-375.

[37] Trinci, A.P.J. (1969) A Kinetic Study of the Growth of Aspergillus nidulans and Other Fungi. J. Gen. Microbiol., 57: 11-24.

[38] Tsujii, K. (1998) Surface Activity: Principles, Phenomena and Applications. 1st edition, Academic Press, San Diego. 
[39] Schmid, A.; Kollmer, A.; Witholt, B. (1998) Effects of Biosurfactant and Emulsification on Two-Liquid Phase Pseudomonas oleovorans Cultures and Cell-Free Emulsions Containing n-Decane. Enzyme Microb. Technol., 22: 487-493.

[40] Kang, Z.; Yeung, A.; Foght, J.M.; Gray, M.R. (2008) Hydrophobic bacteria at the hexadecane-water interface: examination of micrometre-scale interfacial properties. Colloids Surf. B-Biointerfaces., 67: 59-66.

[41] Li, J.; Mcclements, D.J.; Mclandsborough, L.A. (2001) Interaction between Emulsion Droplets and Escherichia coli Cells. J. Food Sci., 66: 570-657.

[42] Franco, J.M.; Raymundo, A.; Sousa, I.; Gallegos, C. (1998) Influence of Processing Variables on the Rheological and Textural Properties of Lupin Protein-Stabilized Emulsions. J. Agric. Food Chem., 46: 3109-3115.

[43] Aronson, M.P.; Petko, M.F. (1993) Highly Concentrated Water-in-Oil Emulsions: Influence of Electrolyte on Their Properties and Stability. J. Colloid Interface Sci., 159: $134-149$.

[44] Esener, A.A.; Roels, J.A.; Kossen, N.W.F. (1981) The bioenergetic correlation of COD to BOD. Biotechnol. Lett. 3: 193-196.

[45] Amini, S.; Mowla, D.; Golkar, M.; Esmaeilzadeh, F. (2012) Mathematical modelling of a hydrocyclone for the down-hole oil-water separation (DOWS). Chem. Eng. Res. Des. 90: $2186-2195$. 


\section{Table captions}

Table 1: Oil properties at $25^{\circ} \mathrm{C}$

Table 2: Composition of the aqueous solution

Table 3: Composition of the nutritive solution (adapted from [37])

Table 4: scale evaluation of the separation of the oil and liquid phase

Table 5: Centrifugal acceleration rate versus the agitation rate (Rhodorsil oil 47v5).

Table 6: Centrifugal acceleration needed versus oil viscosity

Table 7: Dimension of the hydrocyclone used for the model 


\section{Figure captions}

Figure 1: Process to treat hydrophobic VOC in three steps

Figure 2: Time courses of toluene concentration (addition of toluene on day 3 only for the Erlenmeyer containing the biomass)

Figure 3: interfacial tension between oil and water according to the oil used ("new oil" or "used oil') and the water used (ultrapure water, water containing salts and water containing salts and biomass

Figure 4: Photo of the oil in water dispersion after one week of settling

Figure 5: Comparison of the quality of the separation of the dispersion for a saline solution without biomass (black symbols) and for a saline solution with biomass after 8 days of agitation (grey symbols) (oil in water dispersions formed at $300 \mathrm{rpm}$; silicone oil used: the Rhodorsil oil 47v5).

Figure 6: Example of separation quality according to demulsifier concentrations and centrifugal acceleration (between 500 and $1000 \mathrm{G}$ )

Figure 7: Demulsifier distribution between oil and water

Figure 8: Demulsifier toxicity assessment: time courses of toluene consumption (the different symbols correspond to the duplicate experiments)

Figure 9: Scheme of the hydrocyclone used for the model

Figure 10: Acceleration in the hydrocyclone versus the height and the radius. Considering the cylindrical geometry of the hydrocyclone, only one plane in presented.

Figure 11: Oil droplet size distribution. 


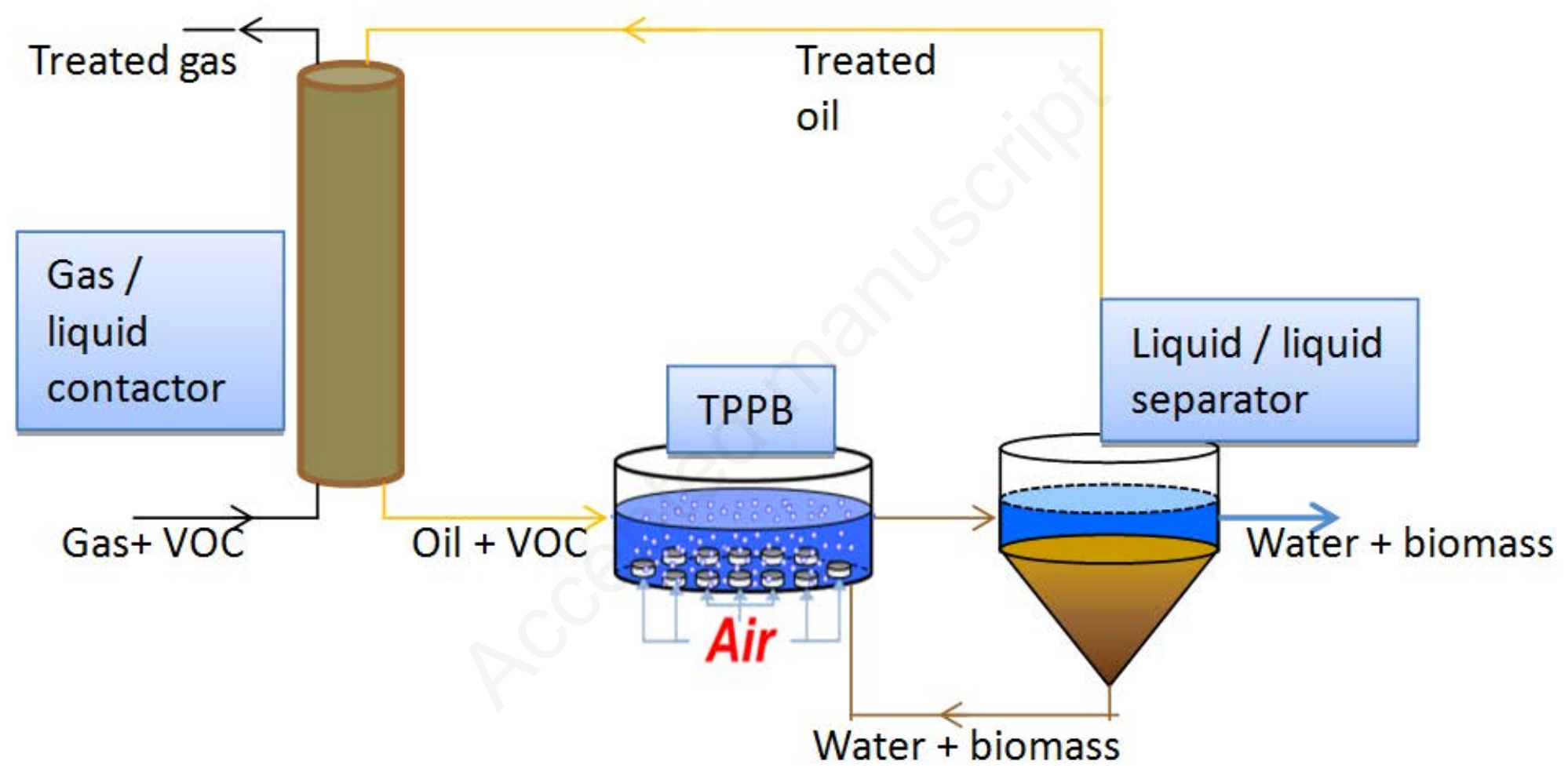




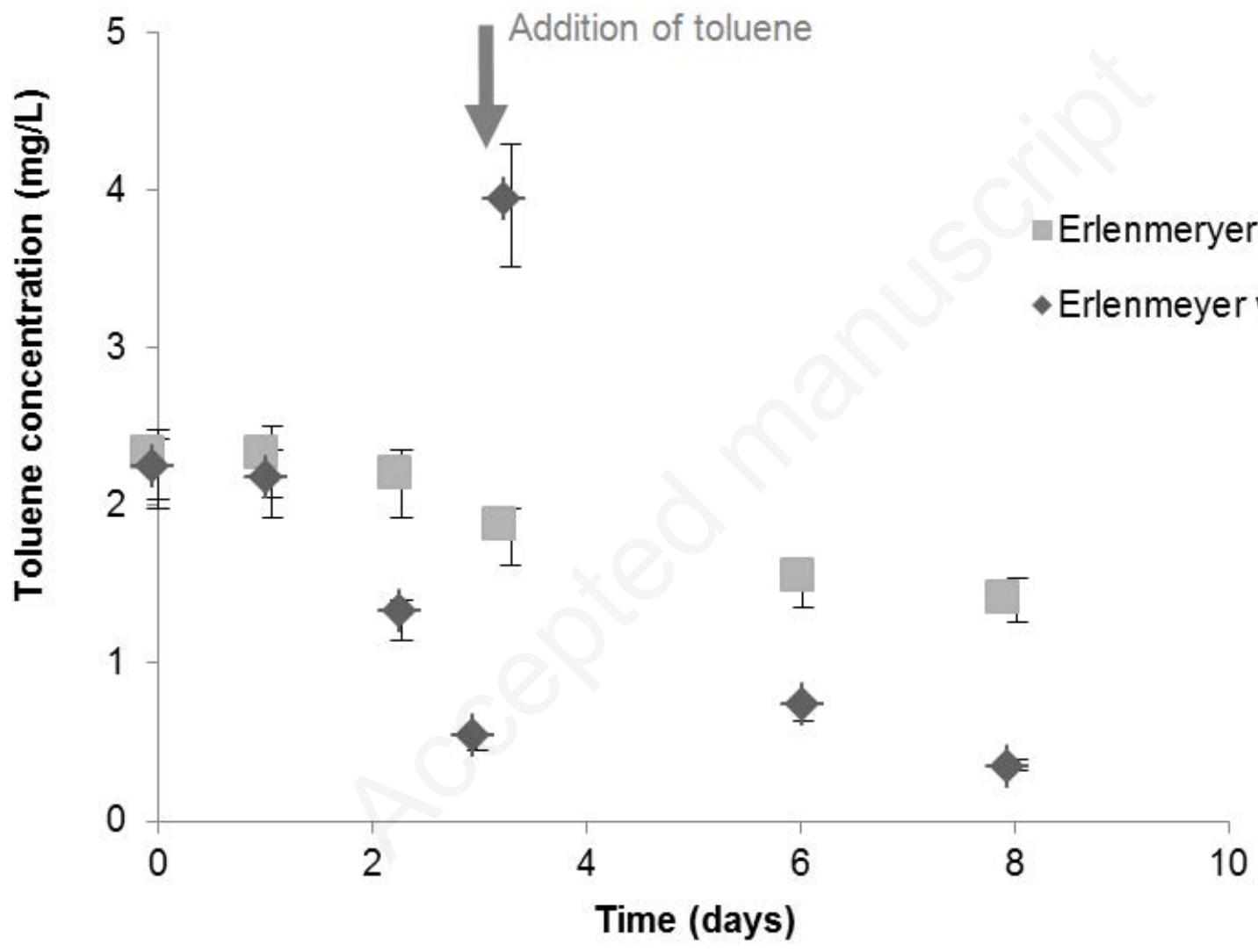




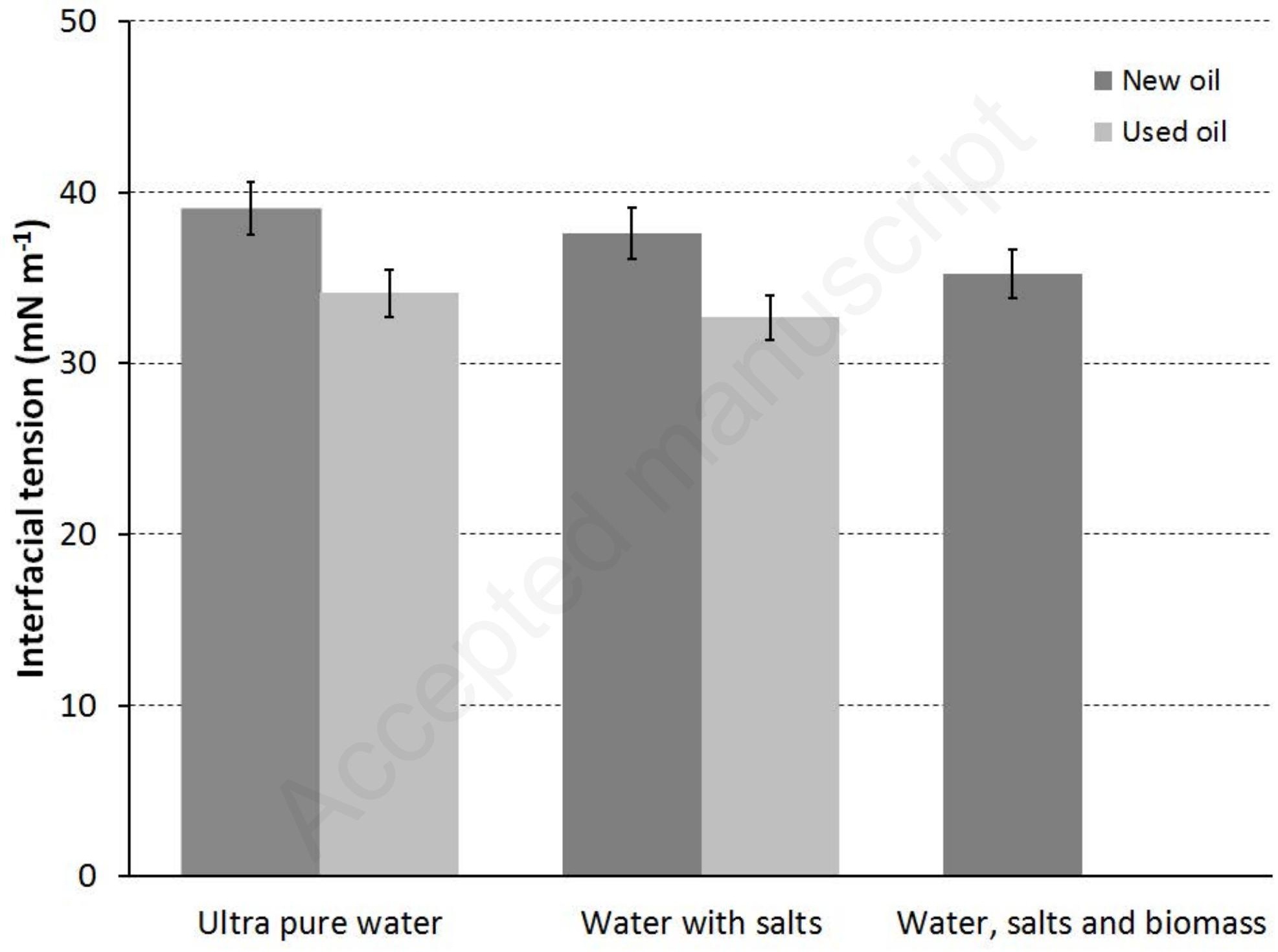



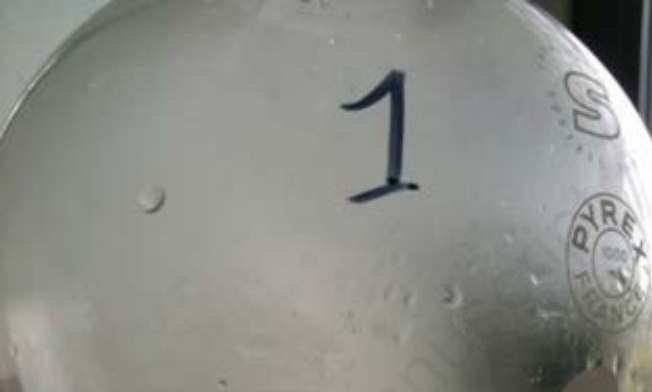


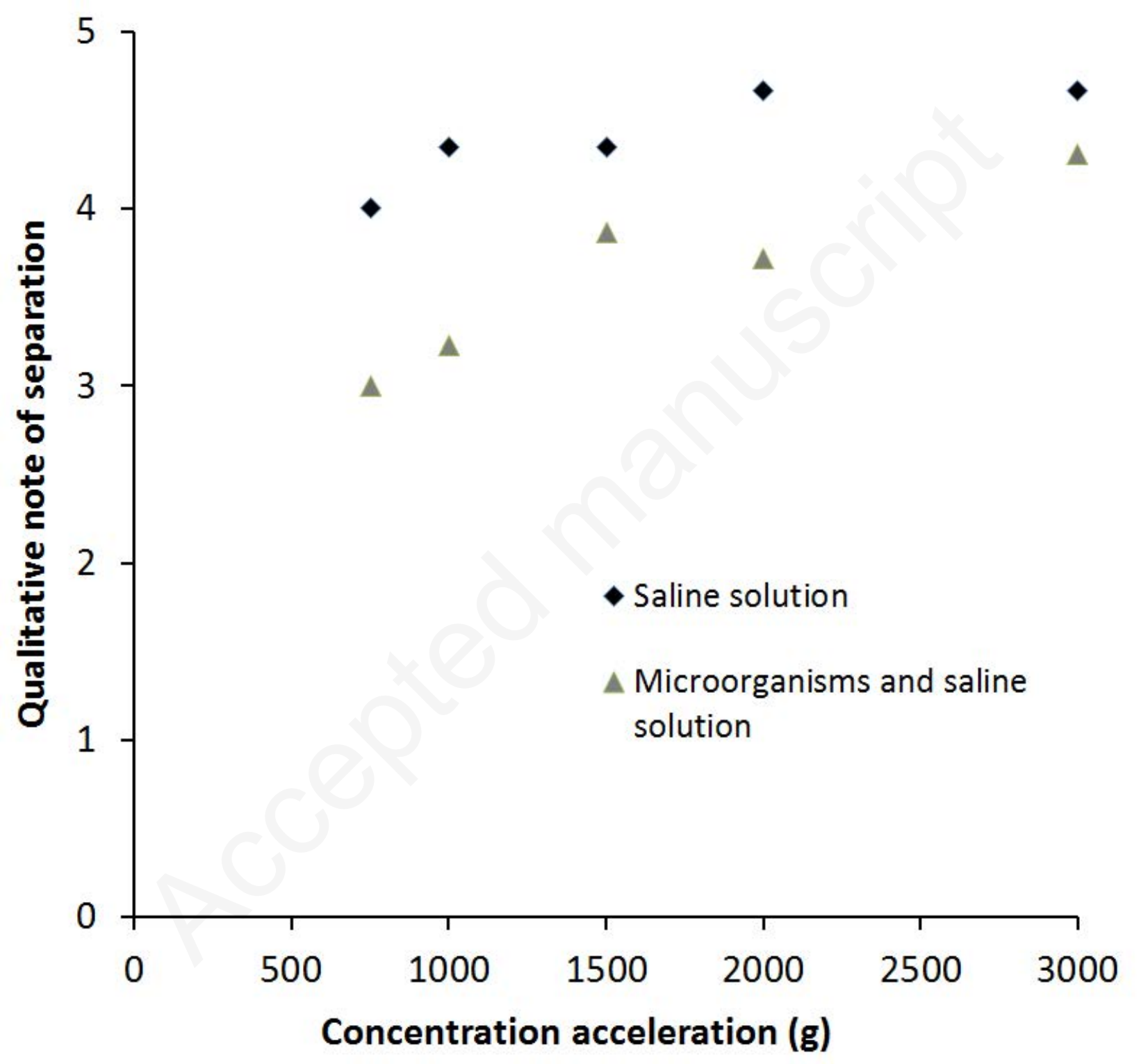




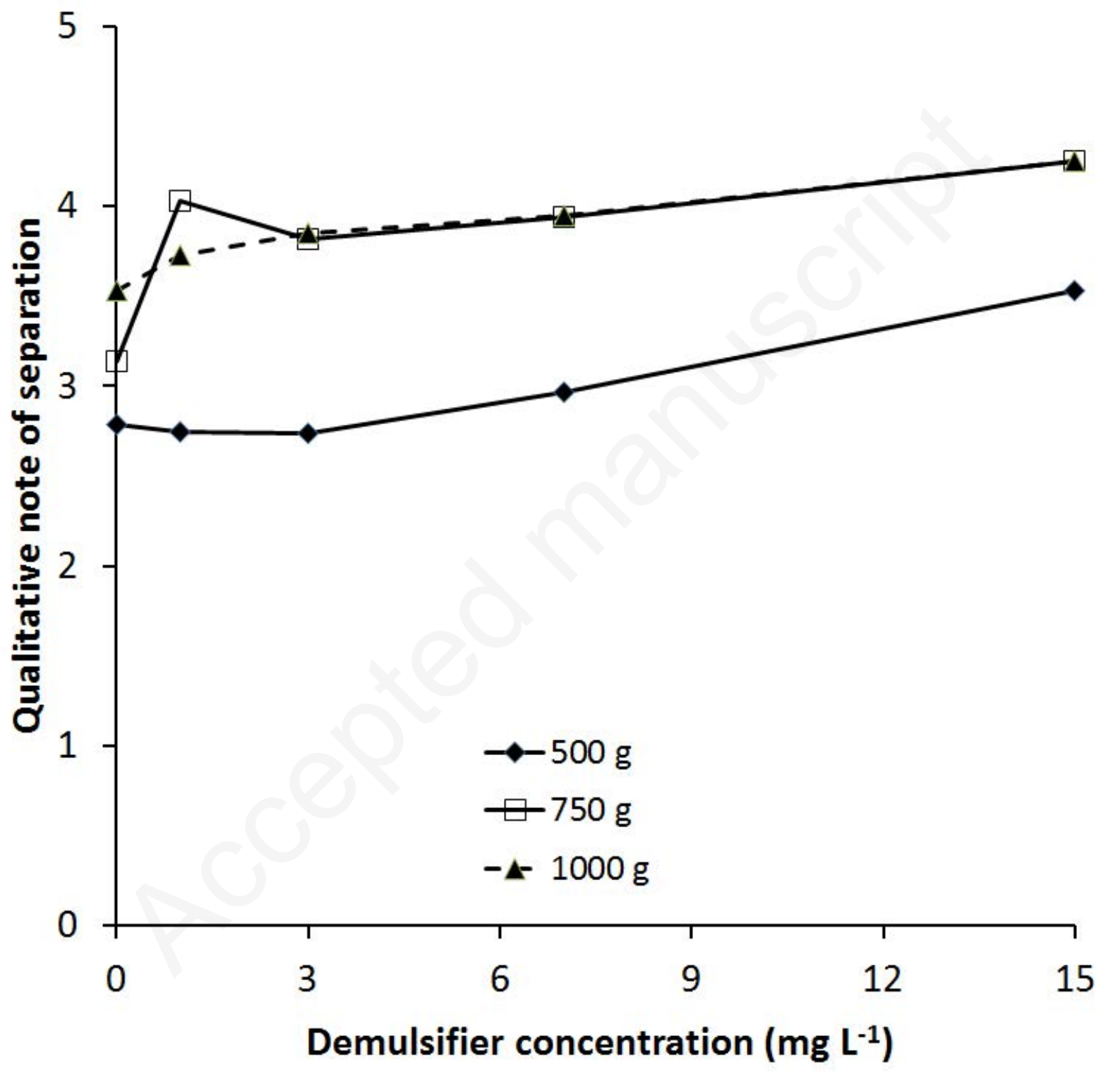




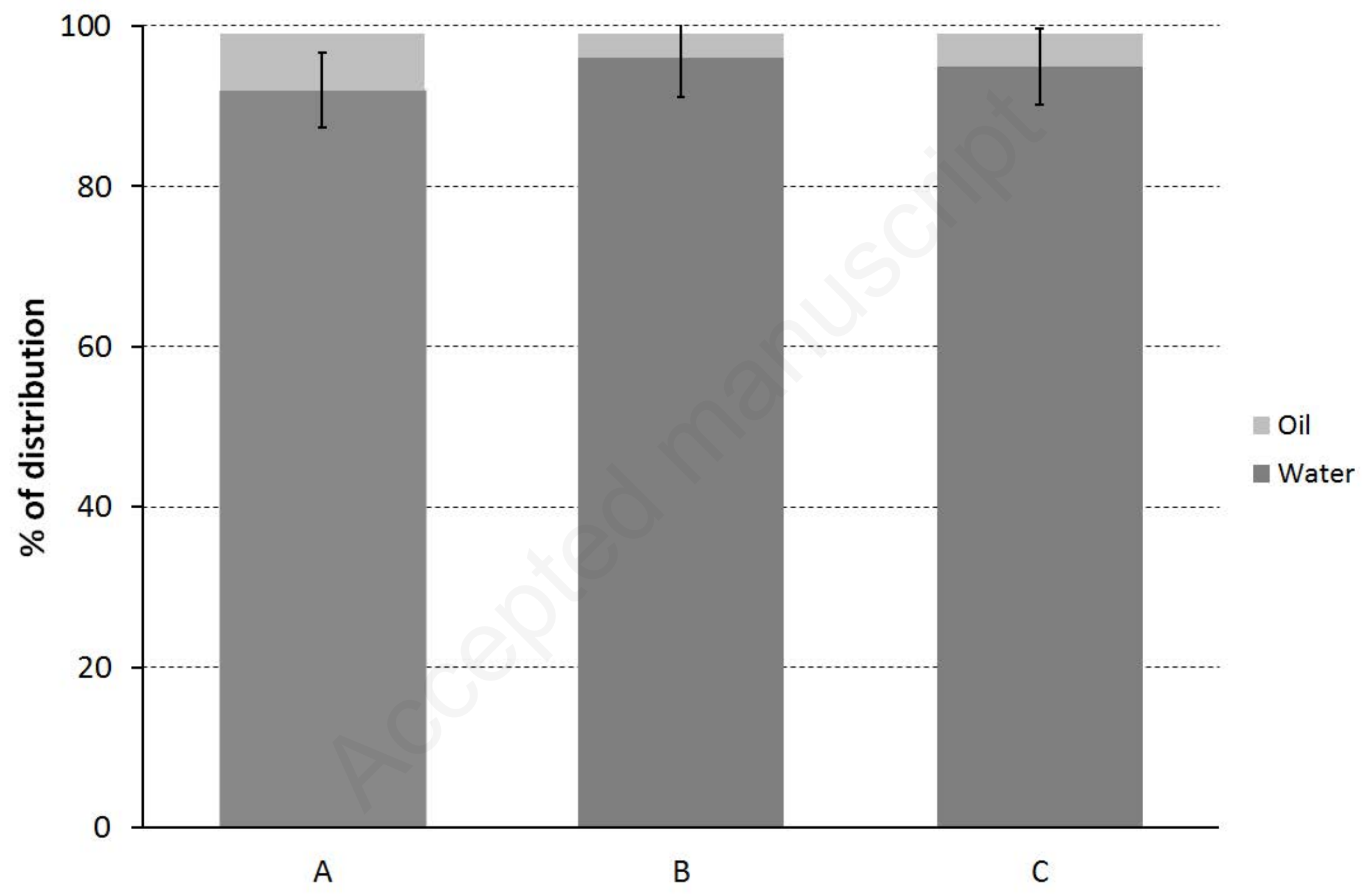


Demulsifier A

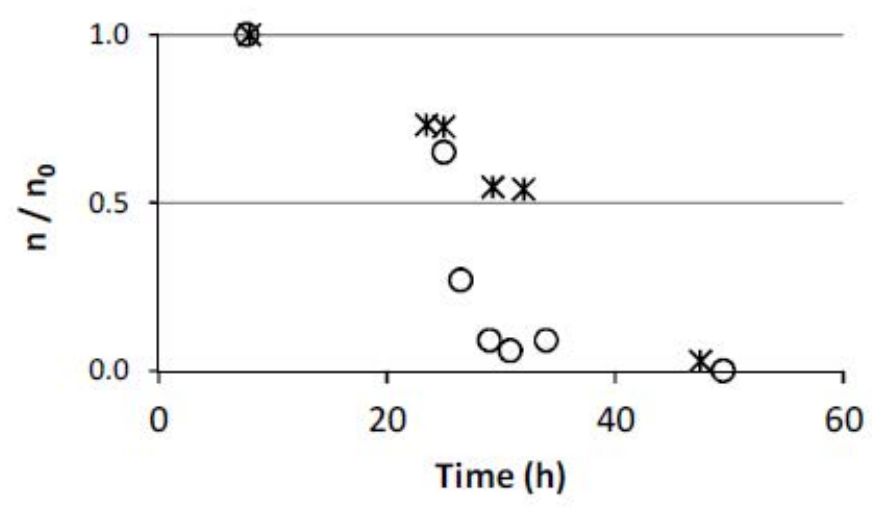

Demulsifier B

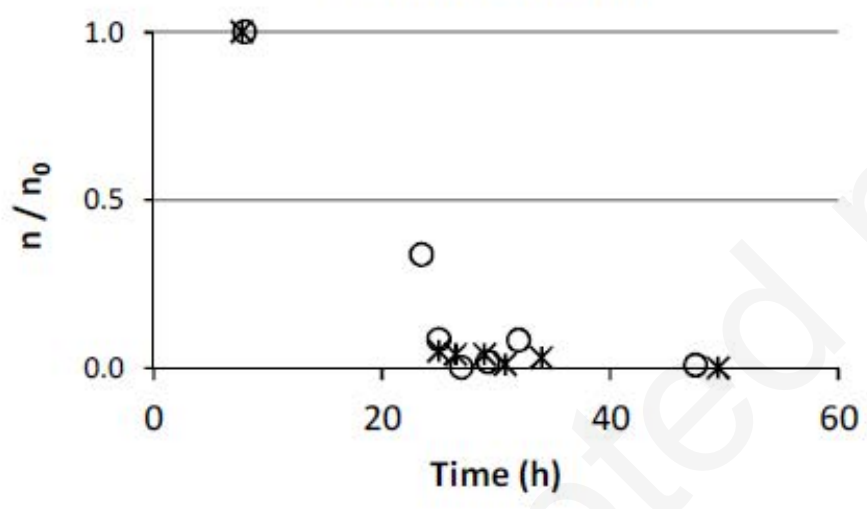

Demulsifier C

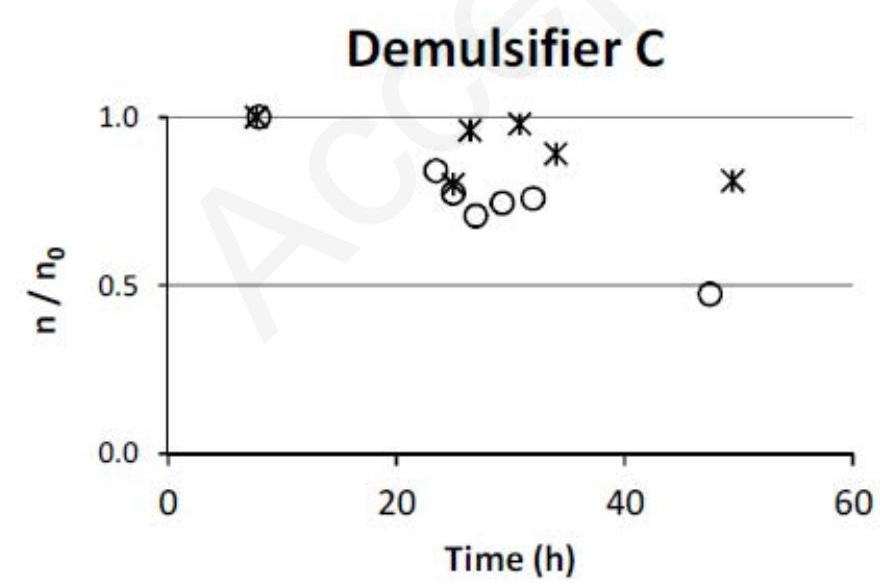

No demulsifier, no biomass

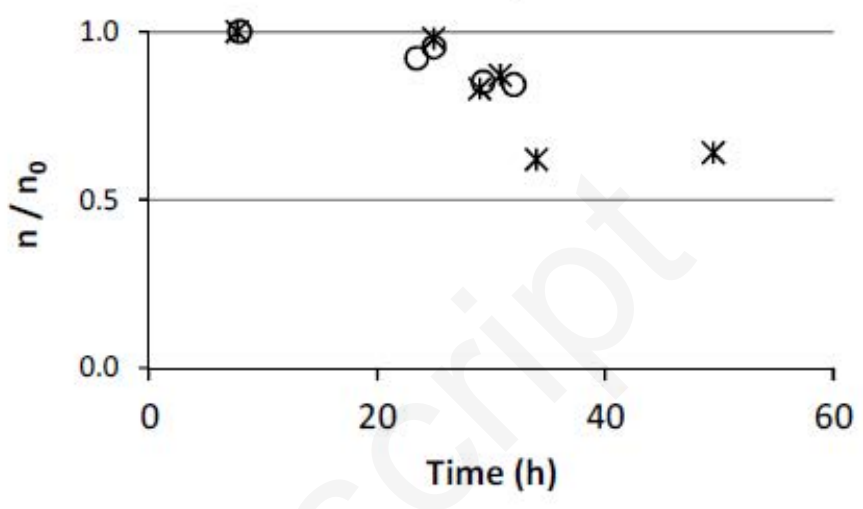

\section{No demulsifier}

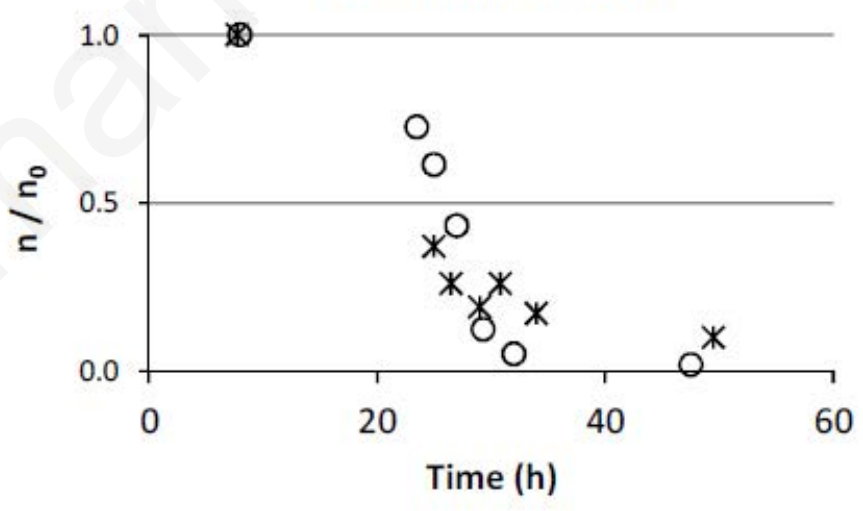


TANGENTIAL

INPUT

亿

natt

CONCENTRATED EMULSION

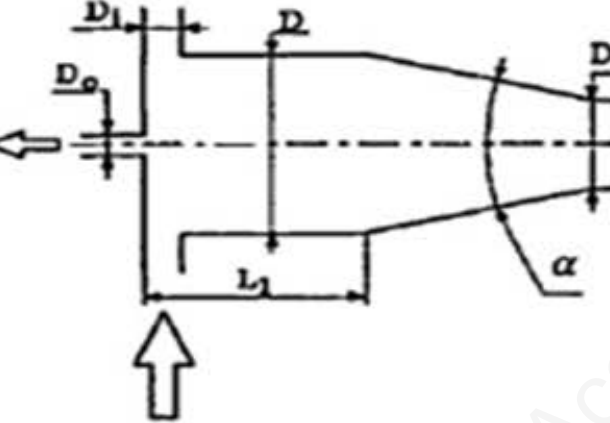

TANGENTIAL

INPIT
Modeled part

$\mathrm{L}_{3}$

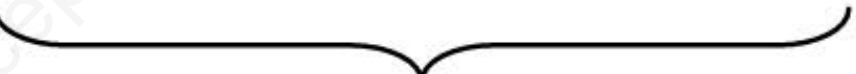


Surface: $\left(\left(w^{\wedge} 2\right) / r\right) / 9.81\left(\mathrm{~m} / \mathrm{s}^{\wedge} 2\right)$

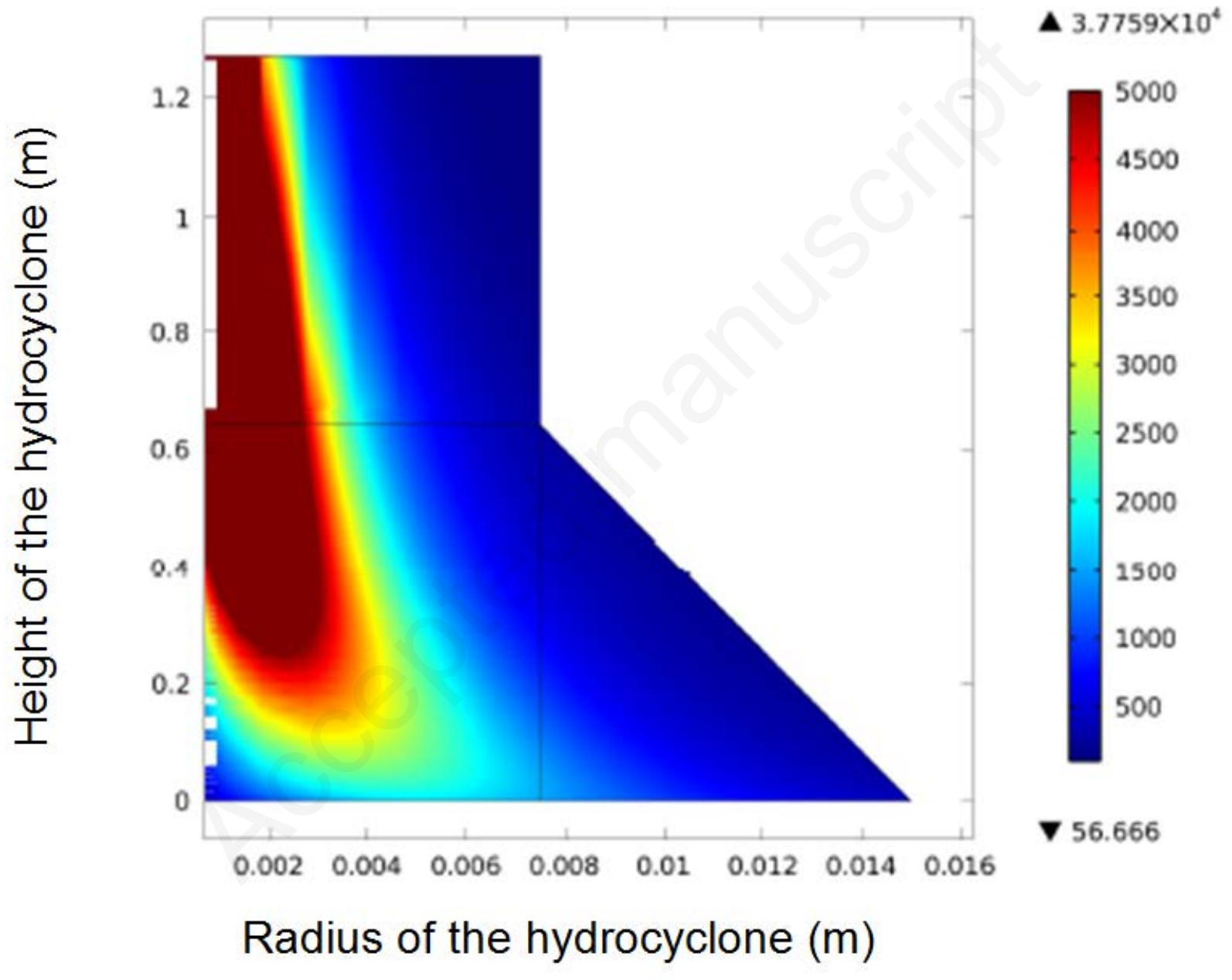




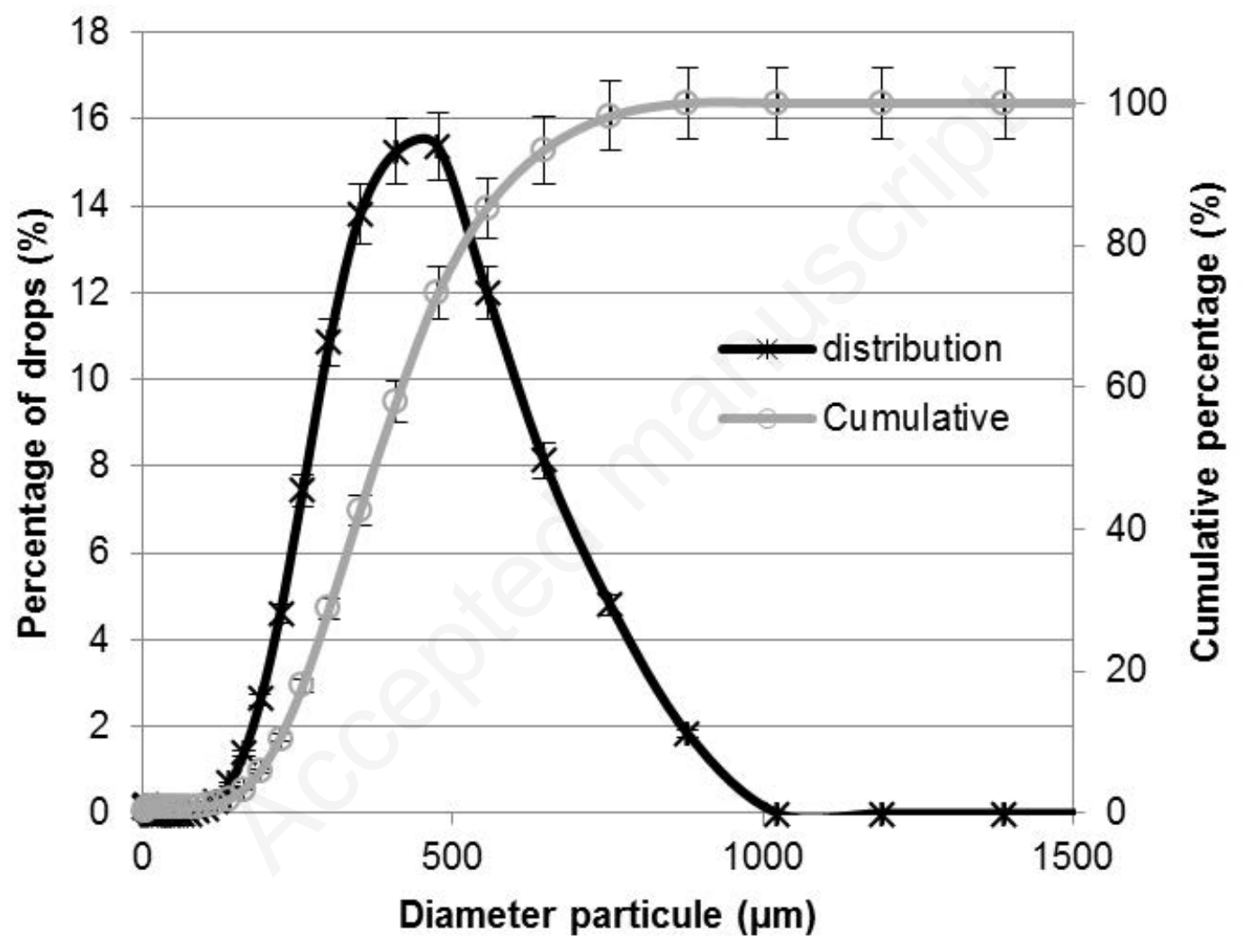


Table 1: Oil properties at $25^{\circ} \mathrm{C}$

\begin{tabular}{cccc}
\hline Properties & $\begin{array}{c}\text { Rhodorsil oil } \\
47 \mathrm{v} 5\end{array}$ & $\begin{array}{c}\text { Rhodorsil oil } \\
47 \mathrm{v} 50\end{array}$ & $\begin{array}{c}\text { Rhodorsil oil } \\
47 \mathrm{v} 100\end{array}$ \\
\hline Dynamic viscosity & $5 \mathrm{mPa} . \mathrm{s}$ & $50 \mathrm{mPa} . \mathrm{s}$ & $100 \mathrm{mPa} . \mathrm{s}$ \\
Density & $910 \mathrm{~kg} \mathrm{~m}^{-3}$ & $959 \mathrm{~kg} \mathrm{~m}^{-3}$ & $965 \mathrm{~kg} \mathrm{~m}^{-3}$ \\
Surface tension & $19.7 \mathrm{mN} \mathrm{m}^{-1}$ & $20.7 \mathrm{mN} \mathrm{m}^{-1}$ & $20.9 \mathrm{mN} \mathrm{m}^{-1}$ \\
& & & \\
\hline
\end{tabular}

Table 2: Composition of the aqueous solution

\begin{tabular}{cc}
\hline Components & Concentrations \\
\hline $\mathrm{NH}_{4} \mathrm{Cl}$ & $5.5 \mathrm{~g} \mathrm{~L}^{-1}$ \\
$\mathrm{KH}_{2} \mathrm{PO}_{4}$ & $3.4 \mathrm{~g} \mathrm{~L}^{-1}$ \\
$\mathrm{Na}_{2} \mathrm{HPO}_{4}, \mathrm{H}_{2} \mathrm{O}$ & $3.8 \mathrm{~g} \mathrm{~L}^{-1}$ \\
Nutritive solution & $50 \mathrm{~mL} \mathrm{~L}^{-1}$ \\
\hline
\end{tabular}

Table 3: Composition of the nutritive solution (adapted from [37])

\begin{tabular}{cc}
\hline Components & Concentrations \\
\hline $\mathrm{MgSO}_{4}, 7 \mathrm{H}_{2} \mathrm{O}$ & $0.25 \mathrm{~g} \mathrm{~L}^{-1}$ \\
$\mathrm{CaCl}_{2}, 2 \mathrm{H}_{2} \mathrm{O}$ & $0.065 \mathrm{~g} \mathrm{~L}^{-1}$ \\
$\mathrm{ZnSO}_{4}, 7 \mathrm{H}_{2} \mathrm{O}$ & $0.02 \mathrm{~g} \mathrm{~L}^{-1}$ \\
$\mathrm{CuSO}_{4}, 5 \mathrm{H}_{2} \mathrm{O}$ & $0.005 \mathrm{~g} \mathrm{~L}^{-1}$ \\
$\left(\mathrm{NH}_{4}\right)_{6} \mathrm{Mo}_{7} \mathrm{O}_{24}, 6 \mathrm{H}_{2} \mathrm{O}$ & $0.0035 \mathrm{~g} \mathrm{~L}^{-1}$ \\
$\left(\mathrm{NH}_{4}\right)_{2} \mathrm{Fe}\left(\mathrm{SO}_{4}\right)_{2}, 6 \mathrm{H}_{2} \mathrm{O}$ & $0.14 \mathrm{~g} \mathrm{~L}^{-1}$ \\
\hline
\end{tabular}

Table 4: scale evaluation of the separation of the oil and liquid phase

\begin{tabular}{lc}
\hline \multicolumn{1}{c}{ Parameters of the efficiency separation } & Weight assigned to each parameter \\
\hline Quantity of drops of oil & 3 \\
Drop size & 5 \\
Dispersion of the drop size & 5 \\
Oil clearness & 7 \\
Aqueous phase clearness & 1 \\
Presence of activated sludge at the interface & 3 \\
Thickness of the interface & 1 \\
\hline
\end{tabular}


Table 5: Centrifugal acceleration rate versus the agitation rate (Rhodorsil oil 47v5).

\begin{tabular}{cc}
\hline $\begin{array}{c}\text { Agitation } \\
\text { speed (rpm) }\end{array}$ & $\begin{array}{c}\text { Value of centrifugal acceleration } \\
\text { for an efficient separation }\end{array}$ \\
\hline 200 & $648-1000 \mathrm{~g}$ \\
300 & $1460-2600 \mathrm{~g}$ \\
550 & $6800-7900 \mathrm{~g}$ \\
\hline
\end{tabular}

Table 6: Centrifugal acceleration needed vers us oil viscosity

\begin{tabular}{cc}
\hline $\begin{array}{c}\text { Oil viscosity } \\
(\mathrm{mPa} \mathrm{s})\end{array}$ & $\begin{array}{c}\text { Value of centrifuge acceleration after } \\
\text { which the phases are separated }\end{array}$ \\
\hline 5 & $1460-2600 \mathrm{~g}$ \\
50 & $7950-13130 \mathrm{~g}$ \\
100 & $7950-13130 \mathrm{~g}$ \\
\hline
\end{tabular}

Table 7: Dimension of the hydrocyclone used for the model

\begin{tabular}{ccccccc}
\hline $\mathrm{D}_{\mathrm{c}}$ & $\mathrm{D}_{\mathrm{n}} / \mathrm{D}_{\mathrm{c}}$ & $\mathrm{L}_{3} / \mathrm{D}_{\mathrm{c}}$ & $\alpha$ & $\beta$ & $\mathrm{D}_{\mathrm{s}}$ & $\begin{array}{c}\text { Emulsion } \\
\text { flow rate }\end{array}$ \\
\hline $60 \mathrm{~mm}$ & 0.5 & 21 & 10 & 0.67 & $16 \mathrm{~mm}$ & $60 \mathrm{~L} \mathrm{~h}^{-1}$ \\
\hline
\end{tabular}

